NBER WORKING PAPER SERIES

\title{
CAPITAL-LABOR-ENERGY SUBSTITUTION IN NESTED CES PRODUCTION FUNCTIONS FOR CHINA
}

\author{
Keting Shen \\ John Whalley \\ Working Paper 19104 \\ http://www.nber.org/papers/w19104
NATIONAL BUREAU OF ECONOMIC RESEARCH
1050 Massachusetts Avenue
Cambridge, MA 02138
June 2013

We are grateful to the Ontario Research Fund (ORF) for financial support, to seminar participants at UWO for comments, and to Aaron Gertz and Chunbing Xing for interactions. The views expressed herein are those of the authors and do not necessarily reflect the views of the National Bureau of Economic Research.

NBER working papers are circulated for discussion and comment purposes. They have not been peerreviewed or been subject to the review by the NBER Board of Directors that accompanies official NBER publications.

(C) 2013 by Keting Shen and John Whalley. All rights reserved. Short sections of text, not to exceed two paragraphs, may be quoted without explicit permission provided that full credit, including $\odot$ notice, is given to the source. 
Capital-Labor-Energy Substitution in Nested CES Production Functions for China

Keting Shen and John Whalley

NBER Working Paper No. 19104

June 2013

JEL No. C61,C68,Q43,Q54

\begin{abstract}
$\underline{\text { ABSTRACT }}$
In the CGE based policy modeling literature, especially recent literature on policy modeling for global climate change, nested CES production functions over multiple inputs have been widely used. Although lack of reliable estimates of substitution elasticities for nested structures has been acknowledged for a long time, the problem has not yet been solved satisfactorily. This is especially the situation for the Chinese case for which modeling work has global implications. This paper reports estimates of substitution elasticities for normalized nested CES aggregate production functions for China with different nested structures of input factors: capital, labor with or without human capital adjustment, and energy using data for the period 1979-2006. We adopt grid search based non-linear optimization techniques for estimation. The results show that all the substitution elasticities we estimate are positive. For the widely used $(\mathrm{K}, \mathrm{L}) \mathrm{E}$ structure, we find that the substitution elasticity between capital and labor for China is below unity. When human capital adjusted labor is used as input instead of unadjusted raw labor, estimates of substitution elasticity between capital and labor become lower. By considering the significance of estimates, our results suggest that the $(\mathrm{E}, \mathrm{L}) \mathrm{K}$ structure seems more appropriate for the Chinese economy.
\end{abstract}

\author{
Keting Shen \\ Department of Economics \\ Zhejiang Gongshang University \\ Hangzhou, 310018 \\ CHINA \\ ktshen1998@gmail.com \\ John Whalley \\ Department of Economics \\ Social Science Centre \\ University of Western Ontario \\ London, ON N6A 5C2 \\ CANADA \\ and NBER \\ jwhalley@uwo.ca
}




\section{Introduction}

This paper presents estimates of substitution elasticities of normalized nested CES aggregate production functions for China with different nested structures using grid search based non-linear estimation procedures and a time series data set for the period 1979-2006. These estimates are motivated mainly by the following concerns: (1) That the substitution elasticity between energy and capital (or labor) for China is central to analyses of the impacts of emission reduction initiatives; (2) That an aggregate capital-labor substitution elasticity greater than one can be used directly to explain China's declining labor share in GDP (where labor is the slower growing factor); (3) That aggregate substitution elasticities between capital and labor for China are dependent on whether or not the labor is adjusted by human capital; and (4) Whether normalization of production function or sample data is important in parameter estimation. The special focus on China is motivated in part by a relative lack of estimates in the literature, and also by the distinct characteristics of the Chinese case. For example, the high growth rate which makes newly produced capital a larger fraction of the capital stock at any point in time. If substitution for existing capital by labor or energy is more difficult, this would suggest higher estimated elasticities for China.

Elasticities of substitution in CES production functions are of great importance for CGE based policy modeling, since the results of counterfactual policy analyses and the comparative static behavior of these models can be highly sensitive to the values used for elasticity parameters. For example, Jacoby et al. (2006) find that the 
elasticity of substitution between energy and value-added (the capital-labor composite) is the key parameter in the MIT EPPA model and significantly affects the costs of a “Kyoto forever” scenario for the U.S. economy. Okagawa \& Ban (2008) estimate nested CES production functions using panel data for OECD countries and suggest that compared with their new estimates, conventional parameter values could overestimate the necessary carbon price by 44\%. Burniaux \& Martins (2012) show that increasing the substitution elasticity between energy and value-added (inter-factor elasticity) induces higher carbon leakage, especially when the joint sensitivity to both inter-factor and inter-fuel elasticities of substitution are considered.

Although lack of reliable estimates of substitution elasticities has been acknowledged for a long time, the problem has not yet been solved satisfactorily (Dawkins et al., 2001). Burniaux et al. (1992) survey earlier literature on the estimation of substitution elasticities between capital, labor, and energy. They conclude that most of the estimates of substitution elasticities between capital and labor lie within the range of 0.5 to 1.5 . Recent empirical evidence suggests that a CES aggregate production function should generally have a below unity substitution elasticity between capital and labor (see Chirinko (2008) and Klump et al. (2011), for example). Surveys of CGE based climate policy modeling show that different quantitative models may differ significantly both in structures of production functions and values of substitution elasticities (see Table 1 in Van der Werf (2008), for example). There are also long-standing controversies on capital-energy substitutability or complementarity (see Solow (1987) and Thompson \& Taylor (1995), for example), 
and the capital-skill complementarity hypothesis formalized firstly by Griliches (1969). For China, low estimates such as these are potentially inconsistent with the conventional understanding of the mechanism that leads to a falling share of the slower growing factor, labor.

In this paper, we report estimates of substitution elasticities of nested CES aggregate production functions for China with different nested structures of input factors capital, labor (or human capital adjusted labor), and energy using normalized data for the period 1979-2006. We use grid search based non-linear estimation techniques. Our results show that all the substitution elasticities we estimate are positive. For the widely used $(K, L) E$ structure, we find that the substitution elasticities between capital and labor for China are below unity. When human capital adjusted labor is used as input instead of unadjusted raw labor, estimates of substitution elasticities between capital and labor become lower. By considering the significance of estimates, our results suggest that the $(E, L) K$ structure seems more appropriate for the Chinese economy.

Although China is often included in much of the recent literature of CGE based climate policy modeling, the lack of reliable estimates of substitution elasticities for China is a special problem. Su et al. (2011) is the most closely related empirical study for China we have found in literature. Su et al. (2011) estimate elasticities of substitution for a two-level nested CES aggregate production function of capital, labor and energy for China with a dataset from 1953 to 2006 (one of the two sub-samples is the market-period 1979-2006) using non-linear estimation methods development by 
Mishra (2006). Our estimates go beyond those in Su et al.'s study in the following areas: (1) That by using normalized CES production functions and grid search based optimization methods, the standard errors of our estimates are comparatively lower; (2) That by considering the significance of estimates, our results suggest a statistically significant nested structure $(E, L) K$ while their estimates show that all three nested structures are insignificant; (3) That by using labor with or without human capital adjustment, our results provide more comprehensive estimates of substitution elasticity between capital and labor.

The rest of the paper is organized as follows. We first introduce the specification of nested CES production functions and dataset we use in estimating substitution elasticities of nested CES functions in section 2. The empirical results are presented in section 3, and we also make a comparison with results in recent literature in this section. Finally, we offer a conclusion in section 4. 


\section{Specification of Nested CES Functions and Data Sets}

We consider a three-factor two-level aggregate production function with inputs capital $(K)$, labor $(L)$ and energy $(E)$. The first level of the two-level CES function is given by a CES function of $K$ and $L$

$$
X=B\left[\beta K^{-\rho}+(1-\beta) L^{-\rho}\right]^{-\frac{1}{\rho}}
$$

Then this first level CES function is nested into the second level function of $X$ and $E$

$$
Y=A\left[\alpha X^{-\theta}+(1-\alpha) E^{-\theta}\right]^{-\frac{1}{\theta}}
$$

Substituting equation (1) into (2) yields the two-level CES function

$$
Y=A\left[\alpha\left(B\left[\beta K^{-\rho}+(1-\beta) L^{-\rho}\right]^{-\frac{1}{\rho}}\right)^{-\theta}+(1-\alpha) E^{-\theta}\right]^{-\frac{1}{\theta}}
$$

Equation (3) gives out one of the three nested structures of the three-factor two-level CES production function of capital $(K)$, labor $(L)$ and energy $(E)$. We denote it as $(K, L) E$.

Accordingly, we can express the other two nested structures of the three-factor two-level CES production function as $(K, E) L$ and $(E, L) K$

$$
\begin{aligned}
& Y=A\left[\alpha\left(B\left[\beta K^{-\rho}+(1-\beta) E^{-\rho}\right]^{-\frac{1}{\rho}}\right)^{-\theta}+(1-\alpha) L^{-\theta}\right]^{-\frac{1}{\theta}} \\
& Y=A\left[\alpha\left(B\left[\beta E^{-\rho}+(1-\beta) L^{-\rho}\right]^{-\frac{1}{\rho}}\right)^{-\theta}+(1-\alpha) K^{-\theta}\right]^{-\frac{1}{\theta}}
\end{aligned}
$$

Although the estimation of the parameters may seem straightforward, there are some problems that need to be addressed further before we have reliable estimates of substitution elasticities for China. Estimating substitution elasticities by using the 
Kmenta approximation or restricted translog functions has been proved unsuitable when an underlying CES function different from the Cobb-Douglas form is used (Thursby \& Lovell, 1978; Henningsen \& Henningsen, 2011). To overcome the issues related to the Kmenta approximation without having to use cumbersome non-linear estimation procedures, researchers have tried to estimate a system of linear equations derived from the first order conditions of cost minimization. However, this approach usually requires comprehensive price data, which in most cases is difficult to obtain and may lead to additional measurement error (Koesler \& Schymura, 2012).

Results based on nonlinear optimization techniques in many cases seem problematic due to convergence problems and yield unstable estimates (Henningsen \& Henningsen, 2012). Furthermore, almost all of the recent literature using non-linear estimation techniques is usually based on un-normalized CES functions. Since there are different measures for input factors capital, labor, and energy (capital in constant 2005 PPP dollars, labor in persons, and energy in million tonnes oil equivalent, for example), we can find that with un-normalized CES functions, that merely a change of measure (change to constant 1995 PPP dollars, for example) may lead to quite different substitution elasticity estimates (see Klump et al. (2011) for a recent survey of the discussion). Last but not least, estimates of substitution elasticities obtained by simply pooling all data across different regions may miss possible differences on substitution elasticities across countries (see Duffy \& Papageorgiou (2000) and Klump et al. (2011) for discussion on related issues).

In order to eliminate potential impacts for substitution elasticity estimates that 
different measures of input factors may have, we should normalize equations (3)-(5) before estimation. Here we normalize these two-level CES functions by utilizing the normalization procedure introduced by La Grandville (1989) and advanced by Klump \& De La Grandville (2000) and Klump \& Preissler (2000).

We firstly define a baseline or reference point $\left(Y_{0}, K_{0}, L_{0}, E_{0}\right)$. Assume all the three factor markets are competitive, by defining baseline factor shares $\pi_{0}=\frac{r_{0} K_{0}}{Y_{0}}$ and $\pi_{0}{ }^{\prime}=\frac{p_{0}{ }^{X} X_{0}}{Y_{0}}$, let $B=X_{0}\left[\pi_{0} K_{0}{ }^{\rho}+\left(1-\pi_{0}\right) L_{0}{ }^{\rho}\right]^{-\frac{1}{\rho}}, \quad A=Y_{0}\left[\pi_{0}{ }^{\prime} X_{0}{ }^{\theta}+\left(1-\pi_{0}{ }^{\prime}\right) E_{0}{ }^{\theta}\right]^{\frac{1}{\theta}}$, $\beta=\frac{\pi_{0} K_{0}{ }^{\rho}}{\pi_{0} K_{0}{ }^{\rho}+\left(1-\pi_{0}\right) L_{0}{ }^{\rho}}$, and $\alpha=\frac{\pi_{0}{ }^{\prime} X_{0}{ }^{\theta}}{\pi_{0}{ }^{\prime} X_{0}{ }^{\theta}+\left(1-\pi_{0}{ }^{\prime}\right) E_{0}{ }^{\theta}}$, we can rewrite equation (3) as

$$
Y=Y_{0}\left[\pi_{0}^{\prime}\left(\pi_{0}\left(\frac{K}{K_{0}}\right)^{-\rho}+\left(1-\pi_{0}\right)\left(\frac{L}{L_{0}}\right)^{-\rho}\right)^{\frac{\theta}{\rho}}+\left(1-\pi_{0}^{\prime}\right)\left(\frac{E}{E_{0}}\right)^{-\theta}\right]^{-\frac{1}{\theta}}
$$

By allowing for Hicks-neutral technological change in production function, equation (6) can be expressed as

$$
\frac{Y}{Y_{0}}=\xi e^{\lambda t}\left[\pi_{0}{ }^{\prime}\left(\pi_{0}\left(\frac{K}{K_{0}}\right)^{-\rho}+\left(1-\pi_{0}\right)\left(\frac{L}{L_{0}}\right)^{-\rho}\right)^{\frac{\theta}{\rho}}+\left(1-\pi_{0}{ }^{\prime}\right)\left(\frac{E}{E_{0}}\right)^{-\theta}\right]^{-\frac{1}{\theta}}
$$

By further considering parameter for returns to scale $v$, we have

$$
\frac{Y}{Y_{0}}=\xi e^{\lambda t}\left[\pi_{0}{ }^{\prime}\left(\pi_{0}\left(\frac{K}{K_{0}}\right)^{-\rho}+\left(1-\pi_{0}\right)\left(\frac{L}{L_{0}}\right)^{-\rho}\right)^{\frac{\theta}{\rho}}+\left(1-\pi_{0}{ }^{\prime}\right)\left(\frac{E}{E_{0}}\right)^{-\theta}\right]^{-\frac{v}{\theta}}
$$

In addition to considering raw (unadjusted) labor $(L)$ as input in our nested CES specifications as equations (6) and (7), we also examine whether labor input adjusted for human capital accumulation might change the results: 


$$
\begin{aligned}
& \frac{Y}{Y_{0}}=\xi e^{\lambda t}\left[\pi_{0}^{\prime}\left(\pi_{0}\left(\frac{K}{K_{0}}\right)^{-\rho}+\left(1-\pi_{0}\right)\left(\frac{H L}{H L_{0}}\right)^{-\rho}\right)^{\frac{\theta}{\rho}}+\left(1-\pi_{0}^{\prime}\right)\left(\frac{E}{E_{0}}\right)^{-\theta}\right]^{-\frac{1}{\theta}} \\
& \frac{Y}{Y_{0}}=\xi e^{\lambda t}\left[\pi_{0}^{\prime}\left(\pi_{0}\left(\frac{K}{K_{0}}\right)^{-\rho}+\left(1-\pi_{0}\right)\left(\frac{H L}{H L_{0}}\right)^{-\rho}\right)^{\frac{\theta}{\rho}}+\left(1-\pi_{0}^{\prime}\right)\left(\frac{E}{E_{0}}\right)^{-\theta}\right]^{-\frac{v}{\theta}}
\end{aligned}
$$

Where HL denotes human capital or “quality” adjusted labor.

The motivation for including human capital or "quality” adjusted labor in these production functions comes primarily from Romer (1986) and Lucas (1988), who both place emphasis on the importance of human capital in accounting for economic growth. Previous empirical studies of economic growth across countries have revealed that production function parameter estimates can change significantly by using some form of human capital adjusted labor as input, see Mankiw et al. (1992) and Caselli et al. (1996), for example. Duffy \& Papageorgiou (2000) have a short survey on earlier literature and makes an explicit comparison on substitution elasticity estimates for an aggregate CES production function with capital and labor.

Equations (7)-(10) present four different specifications of the nested CES structure $(K, L) E$. Correspondingly, we can also use similar specifications to equations (7)-(10) for the other two nested structures of the three-factor two-level CES production function $(K, E) L$ and $(E, L) K$.

The data set used in this paper combine time series from three different sources. The first is Extended Penn World Tables (EPWT) version 4.0 (Marquetti \& Foley, 2011). We extract from the EPWT data set output $Y_{t}$ (Real GDP in chain indexed 
2005 PPP dollars), capital stock $K_{t}$ (net fixed standardized capital stock in 2005 PPP dollars), and labor employed $L_{t}$ (number of employed workers in persons). The second is the 2012 BP Statistical Review of World Energy. We get from this statistical report data on primary energy consumption $E_{t}$ (expressed in million tonnes oil equivalent). The reason why we use EPWT and BP Statistical Review of World Energy data here instead of data from National Bureau of Statistics of China is mainly for comparison of results with other studies.

To construct data on human capital, we use Barro \& Lee (2011) estimates of the average years of schooling in the population over 15 years old (Barro \& Lee v.1.2). Following Caselli (2005), we define human capital as $H_{t}=e^{\varphi\left(s_{t}\right)}$. The human capital or "quality" adjusted labor can then be expressed as

$$
H L_{t}=H_{t} \cdot L_{t}=e^{\varphi\left(s_{t}\right)} L_{t}
$$

We assume the Mincerian return rate of education is $10 \%$, i.e., $\varphi\left(s_{t}\right)=0.1 \cdot s_{t}$. Here $S_{t}$ is the average years of schooling at time $t$. Barro and Lee's (2011) data set of average years of schooling $S_{t}$ is available in every five years from 1950 to 2010. Since $S_{t}$ changes slowly over time, we treat $S_{t}$ as invariant before new data is available.

Since different measures of input factors may have different potential impacts on substitution elasticity estimates, we normalize all the time series of $Y, K, L$, and $E$ with data of the baseline or reference point. For consistency and reliability, we set the geometric average of series as their corresponding reference point (see Klump et al. (2007) for a short discussion of the choice of reference point). 


\section{Empirical Results}

Nested CES functions are non-linear in parameters and the substitution elasticities can not be easily estimated using standard non-linear estimation techniques. Results based on the nonlinear optimization techniques in many cases may seem problematic due to tricky implementation and convergence problems and yield unstable estimates (Henningsen \& Henningsen, 2012).

Markandya and Pedroso-Galinato (2007) estimate multi-level CES production functions by a nonlinear estimation method in the STATA program which uses an iterative procedure to find the parameter values in the relationship that cause the sum of squared residuals (SSR) to be minimized. It starts with approximate guesses of the parameter values and computes the SSR. The iteration process continues until it finds final convergence where changes slightly in any direction for the parameter values would cause the SSR to increase. Mishra (2006) tests five different optimization methods including Rosenbrock-Quasi-Newton (RQN), Differential Evolution (DE) and Repulsive Particle Swarm (RPS) methods by simulating data generated from two-level CES production functions. He finds that two global optimization methods, DE and RPS, perform better than other more popularly used methods of nonlinear regression. Su et al. (2011) estimate substitution elasticities of two-level CES production functions for China using Mishra's (2006) method. In order to improve further the accuracy of estimation, they perform a nonlinear regression fitting process after applying Mishra’s method and make use of the estimated results as the initial values of the fitting regression. 
Henningsen \& Henningsen (2011) develop an R-package micEconCES to estimate the CES function directly using different nonlinear optimization algorithms. As a further explanation of their package, Henningsen \& Henningsen (2012) distinguish three factors that often cause severe problems when estimating CES functions by non-linear optimization algorithms and the corresponding methods for alleviating or solving these problems: (i) removing discontinuities by using limits, (ii) removing rounding errors by using local linear approximations, and (iii) overcoming problems with an ill-behaved objective function by using a grid search procedure. Their package also includes three global optimization methods, namely, the Nelder-Mead routines (NM), the Simulated Annealing algorithm (SANN), and the Differential Evolution algorithm (DE). Koesler \& Schymura (2012) estimate three-level CES production functions using the non-linear estimation procedures based on micEconCES. Their findings show that compared to standard linear estimation using the Kmenta approximations, non-linear estimation techniques perform significantly better.

We adopt grid search based non-linear estimation procedures in this paper by using the R-package micEconCES. In contrast to the methods used by Koesler \& Schymura (2012), we firstly run different nonlinear optimization algorithms in micEconCES and derive intervals for the two substitution elasticities due to these different estimates, then set intervals two or three times larger than those estimated in previous steps and perform grid search procedures. Finally we recalculate results using those different nonlinear optimization algorithms with values of substitution 
elasticities derived from grid search as starting points, and find the best fitting estimates.

Recent literature estimates nested CES production functions at both an aggregate and sectoral level with different data sets and estimation techniques. For example, Kemfert (1998) estimates the substitution elasticity of all three different nested structures for CES functions of capital, labor, and energy using the non-linear estimation techniques in Shazam for aggregate German industry and seven industrial sectors, and finds that CES production functions with a (KE)-L nesting structure describe Germany's aggregate industry production behavior the best, while a (KL)-E structure fits the sectoral data better. Van der Werf (2008) estimates the parameters of the two-level CES production functions of capital, labor, and energy using a system of equations derived from the first order conditions for cost minimization with 2-digit industry level data from 12 OECD countries. The findings show that the (KL)-E structure fits the data the best and estimates of substitution elasticities are usually considerably lower than one. Okagawa \& Ban (2008) estimate parameters of two-level nested CES functions with the same technique as Van der Werf (2008), using panel data on 14 countries with 19 industries for the period 1995-2004 drawn from a dataset compiled by the EU-KLEMS project of EU. They find higher values of substitution elasticities closely related to energy inputs for energy-intensive industries and lower values for other industries compared to the values often used in existing models. Su et al. (2011) estimate substitution elasticities for a two-level nested CES aggregate production function of capital, labor and energy for China with 
a dataset from 1953 to 2006 (one of the two sub-samples is the market-period 1979-2006). Their results suggest that all the three nested structures fit the data almost equally well, but statistically insignificant.

Our estimates of substitution elasticities for all the three different nested structures of the two-level CES production functions for China both with human capital adjusted labor and raw (or unadjusted) labor are shown in Table 1. The results show that all the estimates of substitution elasticities for three different nested structures of the two-level CES production functions for China, no matter using labor with or without human capital adjusted, almost have the same goodness of fit, with a $R^{2}$ round to 0.9989 . These results are similar to Su et al.'s (2011) estimates which have a $R^{2}$ round to 0.9997 , while different to Kemfert's (1998) for Germany economy which have a $R^{2}$ round to $0.9997,0.786$, and 0.9986 for $(K E) L,(K L) E$, and $(E L) K$ structure, respectively.

Our estimates have comparatively higher standard errors (while lower than those of Su et al.'s results), which means that the estimates may have high variances, and may be mainly due to the comparatively small sample size. An alternative choice to alleviate the problem of high variation is to pool together provincial data. However, estimates of substitution elasticities obtained by simply pooling together all data across different regions may also miss possible differences on substitution elasticities across regions, especially when we consider about significant regional disparities on production technology in different part of China. We suggest that a sample of selected provinces with less regional disparities may be used to some extent to avoid this 
problem. Nevertheless, by considering the significance of the estimates, our results suggest that the $(E, L) K$ structure seems more appropriate for the Chinese economy.

This finding is quite different to Su et al. (2011), and also different to Kemfert (1998) for German economy.

Table 1. Estimates of substitution elasticities for two-level normalized CES production functions of China

\begin{tabular}{|c|c|c|c|c|c|c|c|c|}
\hline $\begin{array}{c}\text { Nest } \\
\text { Structure }\end{array}$ & $\begin{array}{c}\text { Estimate of } \\
\begin{array}{c}\sigma \quad \text { with } \\
v=1\end{array}\end{array}$ & $\begin{array}{c}\text { Std. } \\
\text { Error of } \\
\sigma\end{array}$ & $R^{2}$ & $\begin{array}{c}\text { Estimate of } \\
\sigma \text { without } \\
v=1\end{array}$ & $\begin{array}{c}\text { Std. } \\
\text { Error of } \\
\sigma\end{array}$ & $\begin{array}{c}\text { Est. of } \\
v\end{array}$ & $\begin{array}{l}\text { Std. } \\
\text { Error } \\
\text { of } v\end{array}$ & $R^{2}$ \\
\hline K, HL & 0.5565 & 0.6095 & \multirow{2}{*}{0.9989} & 0.5562 & 0.4968 & \multirow{2}{*}{1.0828} & \multirow{2}{*}{0.2626} & \multirow{2}{*}{0.9989} \\
\hline$(\mathrm{K}, \mathrm{HL}) \mathrm{E}$ & 0.6648 & 1.1727 & & 0.9670 & 2.6916 & & & \\
\hline $\mathrm{K}, \mathrm{E}$ & 0.5829 & 0.4099 & \multirow{2}{*}{0.9989} & 0.6553 & 0.6044 & \multirow{2}{*}{1.0655} & \multirow{2}{*}{0.2943} & \multirow{2}{*}{0.9989} \\
\hline$(\mathrm{K}, \mathrm{E}) \mathrm{HL}$ & 0.6091 & 0.7827 & & 0.5980 & 0.6350 & & & \\
\hline E, HL & 0.9113 & 2.4950 & \multirow{2}{*}{0.9989} & 0.8113 & 1.9676 & \multirow{2}{*}{1.0367} & \multirow{2}{*}{0.3037} & \multirow{2}{*}{0.9989} \\
\hline$(\mathrm{E}, \mathrm{HL}) \mathrm{K}$ & 0.5755 & 0.1578 & & 0.6014 & 0.2713 & & & \\
\hline $\mathrm{K}, \mathrm{L}$ & 0.7418 & 1.1275 & \multirow{2}{*}{0.9989} & 0.7072 & 1.4294 & \multirow{2}{*}{1.0238} & \multirow{2}{*}{1.0121} & \multirow{2}{*}{0.9989} \\
\hline$(\mathrm{K}, \mathrm{L}) \mathrm{E}$ & 0.5059 & 1.0382 & & 0.6373 & 1.5392 & & & \\
\hline $\mathrm{K}, \mathrm{E}$ & 0.5312 & 0.5756 & \multirow{2}{*}{0.9989} & 0.4356 & 0.6190 & \multirow{2}{*}{0.8635} & \multirow{2}{*}{0.9174} & \multirow{2}{*}{0.9989} \\
\hline$(\mathrm{K}, \mathrm{E}) \mathrm{L}$ & 0.8691 & 1.5440 & & 0.7833 & 7.0084 & & & \\
\hline E, L & 2.8637 & 22.2009 & \multirow{2}{*}{0.9989} & 1.6949 & 9.5032 & \multirow{2}{*}{0.9577} & \multirow{2}{*}{0.9077} & \multirow{2}{*}{0.9989} \\
\hline$(\mathrm{E}, \mathrm{L}) \mathrm{K}$ & 0.6057 & 0.1819 & & 0.5680 & 0.9647 & & & \\
\hline
\end{tabular}

Source: Authors' estimates.

We can also see from Table 1 that when human capital adjusted labor $H L$ is used as input instead of raw (or unadjusted) labor $L$, estimates of substitution elasticities between capital and labor become lower. For example, results in Table 1 show that with constant returns to scale $v=1, \sigma$ between $K-H L$ is 0.5565 , while $\sigma$ between $K-L$ it is 0.7418 ; with variant returns to scale $\nu \stackrel{>}{=}, \sigma$ between $K-H L$ is 0.5562 , while $\sigma$ between $K-L$ it is 0.7072 . We can find similar relationship between 
$(K E)-H L$ vs. (KE)-L, and E-HL vs. E-L. These results seems consistent with Griliches’s (1969) hypothesis on capital-skill complementarity. See also Duffy and Papageorgiou's (2000) estimates with a cross-country datasets. Although Duffy and Papageorgiou (2000) give out estimates of substitution elasticities between capital and labor that are greater than one, we find that their results with human capital adjusted labor $H L$ are also lower than those with raw or unadjusted labor $L$.

Another interesting finding from our estimates is that the estimates of substitution elasticities between capital and labor may systematically lower than one. Note that we have an estimate of $\sigma$ between $K-L$ equals to 0.7072 , close to Su et al.'s (2011) estimate of 0.7676 . Our results may add new evidence to the recent literature arguing that a CES aggregate production function should generally have a below unity substitution elasticity between capital and labor. However, estimates of substitution elasticity between capital and labor lower than one for China are potentially inconsistent with the conventional understanding of the mechanism that leads to a falling share in GDP of the slower growing factor, labor, of the Chinese economy. This finding may suggest that we have to find alternative mechanisms to explain the falling labor share in GDP for China. 


\section{Conclusion}

In the CGE based policy modeling literature, especially recent literature on policy modeling for global climate change, nested CES production functions over multiple inputs have been widely used. Although lack of reliable estimates of substitution elasticities for nested structures has been acknowledged for a long time, the problem has not yet been solved satisfactorily. This is especially the situation for the Chinese case for which modeling work has global implications.

In this paper, we report estimates of substitution elasticities of normalized nested CES aggregate production functions for China with input factors capital, labor (with raw or unadjusted labor and human capital adjusted labor), and energy. In order to have a direct comparison with existing literature, we use a data set for the period 1979-2006. We adopt grid search based non-linear optimization techniques using R-package micEconCES for estimation.

Our results show that estimates of substitution elasticities for all three different nested structures of two-level CES production functions for China, no matter using labor with or without human capital adjusted, all have satisfactory goodness of fit with relatively high $R^{2}$ values. The estimates of substitution elasticities have comparatively higher standard errors, which mean that the estimates may have high variations. Nevertheless, our estimates are a necessary response to a relative lack of estimates for substitution elasticities for China in existing literature. Notably, by considering the significance of estimates, our results suggest that the $(E, L) K$ structure seems more appropriate for the Chinese economy. 
Our estimates address several problems occurred in existing literature estimating substitution elasticities for China, and also provide evidence on the difference of substitution elasticities between physical capital and labor with or without human capital adjustment. Our finding that the substitution elasticity between capital and labor for China below unity may also call into question some earlier literature explaining the falling labor share in GDP with a substitution elasticity above one. 


\section{References}

Barro, R. and J. Lee (2010), "A New Data Set of Educational Attainment in the World, 1950-2010”, NBER Working Paper No. 15902 (Updated Nov./2011).

Burniaux, J., J. P. Martin, G. Nicoletti and J. O. Martins (1992), "GREEN a multi-sector, multi-region general equilibrium model for quantifying the costs of curbing $\mathrm{CO} 2$ emissions: a technical manual”, OECD Economics Department Working Papers No. 116.

Burniaux, J. and J. O. Martins (2012), “Carbon leakages: a general equilibrium view”, Econ Theory, 49:473-495.

Caselli, F. (2005), “Accounting for Income Differences Across Countries”, chapter 9 in the Handbook of Economic Growth Vol. 1A, P. Aghion and S. Durlauf, eds., North Holland.

Chirinko, R. S. (2008), “ $\sigma$ : The Long and Short of It”, Journal of Macroeconomics, 30(2): 671-686.

Dawkins, C., T. N. Srinivasan, J. Whalley, and J. J. Heckman (2001), "Calibration”, in Handbook of Econometrics, Vol. 5, Chapter 58, pp. 3653-3703.

Duffy, J. and C. Papageorgiou (2000), “A cross-country empirical investigation of the aggregate production function specification”, Journal of Economic Growth, 5(1): 87-120.

Griliches, Z. (1969), “Capital-Skill Complementarity”, The Review of Economics and Statistics, Vol. 51, No. 4, pp. 465-468.

Henningsen A. and G. Henningsen (2011), "Econometric Estimation of the Constant Elasticity of Substitution Function in R: Package micEconCES”, FOI Working Paper 2011 / 9.

Henningsen A. and G. Henningsen (2012), "On estimation of the CES production function -Revisited”, Economics Letters, 115: 67-69.

Jacoby, H. D., J. M., Reilly, J. R., Mcfarland, and S. Paltsev (2006), “Technology and technical change in the MIT EPPA model”, Energy Economics, Vol. 28, pp.610-631.

Kemfert, C., (1998), "Estimated substitution elasticities of a nested CES production function approach for germany”, Energy Economics, 20: 249-264.

Klump, R. and O. De La Grandville (2000), "Economic growth and the elasticity of substitution: Two theorems and some suggestions”, American Economic Review, 90(1): 282-291.

Klump, R., P. McAdam and A. Willman (2011), "The Normalized CES Production Function, Theory and Empirics”, European Central Bank Working Paper Series No. 1294.

Koesler, S. and M. Schymura (2012), "Substitution elasticities in a CES production framework: An empirical analysis on the basis of non-linear least squares estimations”, ZEW Discussion Paper No. 12-007.

La Grandville, O. De (1989), “In quest of the Slutzky Diamond”, American Economic Review, 79: 468-481.

Lucas, R. E. (1988), "On the mechanics of economic development," Journal of Monetary Economics, 22: 3-42.

Mankiw, N. G., D. Romer, and D. N. Weil (1992), "A Contribution to the Empirics of Economic Growth,” Quarterly Journal of Economics, 107: 407-437.

Markandya, A. and S. Pedroso-Galinato (2007), "How substitutable is natural capital?" Environmental and Resource Economics, 37 (1): 297-312.

Marquetti A. and D. Foley (2011), Extended Penn World Tables Version 4.0, last updated in Aug./2011.

Mishra, S. (2006) “A note on numerical estimation of sato's two-level CES production function”, 
Social Science Research Network.

Okagawa, A. and K. Ban (2008), "Estimation of substitution elasticities for CGE models", Discussion Papers in Economics and Business, No. 08-16.

Romer, P. M. (1986), “Increasing returns and long-run growth,” Journal of Political Economy, 94: 1002-1037.

Solow, J. L. (1987), “The Capital-Energy Complementarity Debate Revisited”, American Economic Review, 77: 605-614.

Su, X., W. Zhou, K. Nakagami, H. Ren and H. Mu, (2011), "Capital stock-labor-energy substitution and production efficiency study for China”, Energy Economics, 34 (4): 1208-1213.

Thompson, P. and T. Taylor, (1995), “The capital-energy substitutability debate: A new look”, Review of Economics \& Statistics, 77: 565-569.

Thursby, J. G. and C. K. Lovell (1978), "In investigation of the Kmenta approximation to the CES function”, International Economic Review, 19(2): 363-377.

Van der Werf, E. (2008), "Production Functions for Climate Policy Modeling: An Empirical Analysis”, Energy Economics, 30: 2964-2979. 